\title{
Perpetuating Oppression: Does the Current Counseling Discourse Neutralize Social Action?
}

\author{
Arie T. Greenleaf \\ University of Arkansas \\ Rhonda M. Bryant \\ Albany State University
}

\begin{abstract}
The counseling profession, by virtue of research, dialogue, and the evolution of professional ideology, continues to uphold the viewpoint that psychological distress and disorders emanate from innate or biologically based factors. Consequently, the social reality that counseling partially defines through this discourse may inadvertently constrain the very movement that can most affect change through social action and engagement. Counseling professionals may unwittingly undercut attempts by oppressed individuals, groups, and their allies to create a more equitable and just society through civil disobedience and concerted social action. This article discusses how the current discourse on social justice may neutralize social action by reviewing discourse theory and presentation of a case study that offers strategies to operational discourse theory and support social action and engagement.
\end{abstract}

Keywords: counseling and social justice, discourse theory, oppression

The goal of social justice counseling is to foster an environment where all individuals can enjoy full and equal participation in society (Toporek, Gerstein, Fouad, Roysircar, \& Israel, 2006). Counselors work toward this goal through both direct counseling to empower clients and students to become self-advocates as well as through personal advocacy at the community, systemic, and socio-political levels (Lewis, Arnold, House, \& Toporek, 2003). Although many recent publications highlight the need for counselors to act as agents of social change (e.g., Baluch, Pieterse, \& 
Bolden, 2004; Greenleaf \& Williams, 2009; Kiselica \& Robinson, 2001; Lee, 1998; Lewis \& Arnold, 1998; Myers, Sweeney, \& White, 2002; Ratts, 2009; Vera \& Speight, 2003), the profession would benefit from more discussion on how to meet this need. The primary challenge seems related to a majority of persons within the field who neither address social justice and its impact on client's well-being nor engage in the purposeful action needed to change societal injustices (D'Andrea \& Daniels, 1999; Ratts, 2009; Vera \& Speight, 2004).

A number of counseling professionals (Albee, 1990; Greenleaf \& Williams, 2009; Ivey \& Ivey, 2005; Lewis \& Arnold, 1998; McWhirter, 1997; Prilleltensky, 2008; Ratts, 2009; Smith, Baluch, Bernabei, Robohm, \& Sheehy, 2003; Sue \& Sue, 2008; Worell \& Remer, 2003) have argued that helping professions have failed in their ethical responsibility to address societal barriers because an intrapsychic perspective reigns as the dominant paradigm of the profession. Since an intrapsychic perspective conceptualizes human problems as being solely biologically- or psychologically-based phenomena that originate and exist internally. Thus, counselors fail to make the connection between their clients' problems and the injustices that exist externally within the social order (Baluch, Pieterse, \& Bolden, 2004; D'Andrea, 2002; Greenleaf \& Williams, 2009; Jacobs, 1994).

A major consequence of a one-sided intrapsychic discourse on human problems is that factors within the client's environmental sphere (social, economic, cultural, and political) (Breton, 1995) may go largely unaddressed in the assessment, problem formulation, and treatment planning stages. As a result, counselors convey an incomplete message as they lay problems solely at the feet of personal dysfunction and/or deficiency, without regard for the social toxins inherent in their clients' environment.

To broaden this single focus and to provide the philosophical raison d'être for social justice counseling, Greenleaf and Williams (2009) promoted the inclusion of an ecological perspective, defined as "the importance of understanding behavior in sociocultural context and as influenced by multiple levels of the ecological environment" (Trickett, 1997, p. 198). Because an ecological perspective conceptualizes human Behavior as a result of Person-Environment interaction, formulated as $B=f(P X E)$ (Lewin, 1936), the link between environmentally-based oppression and personal symptoms of psychopathology is highlighted and supported theoretically. Without a better understanding of the ecological perspective, Greenleaf and Williams (2009) argued, counseling professionals are likely to continue to overlook the need for social justice advocacy. In other words, as long as counselors bring an almost exclusive, internally-based perspective, or B = $f(P)$, to addressing their clients' problems, they are unlikely to devote any professional time and energy toward lifting oppressive conditions in the social order.

The authors note that the literature documents empirical support for psychotherapeutic interventions in addressing successfully a myriad of human problems and thereby enhancing the quality of people's lives. However, the counseling profession could increase its range of effectiveness by incorporating into its approach a greater recognition of the impact derived from negative environmental conditions. With this in mind, this article clarifies the consequences related to the profession's current emphasis on intrapsychic discourse and how this entrenched approach may actually maintain an oppressive social order. 


\section{Perpetuating Oppression}

The counseling profession's dominant use of intrapsychic discourse, implicit in the profession's inherent message to clients and society, maintains that human problems primarily stem from personal malfunction within the individual. Consequently, the exclusive focus on a client's internal issues while ignoring interventions to alter oppressive, external factors in that individual's social realm perpetuates, in effect, the status quo within the social order. Since helping professionals exercise moral and intellectual leadership in society (Albee, 2004; Szasz, 1961), their professional discourse (beliefs, attitudes, explanations, courses of action) systematically produces the 'truths' from which society makes meaning about the 'reality' of psychological distress and disorders. In other words, the discourse that helping professionals use to explain mental, emotional and behavioral phenomena shapes society's assumptions and beliefs about the nature of the reality of these phenomena. Hence, since the current discourse focuses heavily on intrapsychic and biological processes to explain human problems in living, the view propagated throughout society purports that an individual's behavioral functioning is, for all practical purposes, explained neatly by personal factors within the individual, or $B=f(P)$.

\section{Overview of Discourse Theory}

A review of discourse theory offer a number of important insights into how helping professionals can strengthen their effectiveness in removing social and institutional barriers. Discourse, as articulated by the postmodernist thinker Ernest Laclau (1993), represents a constructed view of reality: "the very possibility of perception, thought, and action depends on the structuration of a certain meaningful field which pre-exists any factual immediacy" (Laclau, 1993, p. 431). In other words, pre-existing an individual's perceptions, thoughts, and actions toward an object or phenomenon, is a discourse that explains the perceived reality of the object or phenomenon. Though objects and phenomena inhabit the real world and exist independently of discourse, discursive articulation is necessary to give meaning to what exists. Laclau and Mouffe (2001) argue that no object or phenomenon has innate meaning, but discourse always articulates meaning. Therefore, "meaning is a social production, a practice. The world has to be made to mean" (Hall, 2006, p. 134). This suggests that reality can be explained through a multitude, even an infinite number of ways. However, typically those with the power and means of communication create the dominant discourses, thus wielding great influence to construct the "truths", "morals", and "norms" that govern social reality (Foucault, 1972).

Discourse, therefore, represents a potentially powerful force in the creation and perpetuation of social inequalities. The poststructuralist philosopher, Michel Foucault, offered and expounded upon insights into the ways dominant groups use discourse as a means of social control. In the simplest form, Foucault (1972) believed that discourse is essentially conversation, or knowledge. However, he astutely observed that everything we think we know as truth or knowledge was established through the use of power. In other words, since "history is written by the victors", those in control have the power to write the unwritten laws (i.e., truth, morality, norms, meaning) that govern human society and ultimately, individual human behavior. As a means of protecting the knowledge produced by the discourse, the powerful create societal institutions to entrench the 'truths' into the fabric of society. Ultimately then, discourse is a means of control via conformity to particular norms, values, and morals that legitimate the current socio-power configurations. 
As an example, the notion of meritocracy has been a dominant theme in American discourse. Consequently, most Americans share a common understanding of what comprise 'good' morals and behaviors, specifically in regards to achieving the 'American Dream'. However, much evidence renders meritocracy a myth (McNamee \& Miller, 2004; Wolff, 2002) and social mobility, a more realistic appraisal of a growing middle class, has declined precipitously in recent decades (Lardner, Lardner, \& Smith, 2006). Despite this evidence, those who do not embrace meritocratic individualism, or openly question the fairness of free-market Capitalism, are frequently marginalized by a wide swath of the population, including many of the dominant institutions, as anti-American, 'socialists'. Thus, discourse ultimately operates by "rules of exclusion": discourse, in the hands of the powerful, controls the objects (what can be spoken of), the ritual (where and how one may speak), and the privilege to speak (who may speak).

\section{How Discourse Operates}

In light of discourse's influence on shaping perceptions of the world, and its ability to generate the knowledge that people accept as truth, it is imperative as helping professionals that we critically examine our discourse and its outgrowth in professional practice. To help gain these insights, counselors must understand first how discourse operates. Foucault (1972) recognized that discourse works in three primary ways: discourse enables, constrains, and constitutes. For example, a counseling discourse enables professional counselors to act as mental health professionals to assess, diagnose, and treat their clients' problems; it constrains what counselors say about the nature of those problems (e.g., professional counselors would not blame their client's depression on witchcraft); and it constitutes professional counseling as a legitimate helping profession. Thus, a counselor derives direction from discourse, which in turn creates the 'reality' of counseling by providing the 'script' that counselors perform. Likewise, a counseling discourse enables, constrains, and constitutes the nature of the issues addressed in therapy. Counselors speak about a behavioral phenomenon, such as depression, in a particular way, and in doing so they enable and constrain what can be said about the condition. In speaking about depression, the counselor constructs a phenomenon of study that becomes a specific diagnosable reality. For example, the DSM-IV-TR constitutes major depressive disorder as an Axis I disorder (constitute). Counselors diagnose this disorder when a client's symptoms match a majority of the criteria factors (enable). Consequently, an intrapsychic-based, pathological condition explains the 'reality' of depression. This discourse disallows and does not acknowledge other interpretations of depression, such as depression is a natural, and perhaps, beneficial response to the environmental stressors associated with injustices in the social order (constrain).

\section{Promoting Hegemonic Truths}

Though all disciplines have a dominant discourse to define the normative guidelines from which members presume their professional responsibilities, practices, and ethics, the concern about counseling's intrapsychic discourse relates to its hegemonic value in maintaining society's status quo. Hegemony, as Gramsci $(1994,2006)$ envisioned it, is a political science concept developed to explain why oppressed social classes have not risen up in Western democracies against the exploitative and oppressive nature of unregulated Capitalism. Gramsci $(1994,2006)$ posited that revolution has been held in check because in a hegemonic culture the subordinate groups accept the interests, values, and meanings of the dominant groups as the 'natural' or 'common sense' principles of all: 
In this sense, the concept is used to suggest a society in which, despite oppression and exploitation, there is a high degree of consensus, a large measure of social stability; a society in which subordinate groups and classes appear to actively support and subscribe to values, ideals, objectives, cultural and political meanings, which bind them to, and "incorporate" them into, the prevailing structures of power (Storey, 2006, p. 63-64).

Gramsci (1994) contends that the prevailing structures of power incorporate subordinate groups through acceptance of a common understanding of what is 'natural' and 'moral'. Thus, despite inequality and oppression, subordinate groups accept the current arrangement of the social order as 'normal' and unassailable because they believe that the hegemonic group's interests, values, and meanings, which create the dominant discourse of the social order, are inherently moral, beneficial and equitable for everyone. Thus, dominant groups (blocs) maintain their control through the production of 'hegemonic truths' - the interests, values, and meanings that unwittingly allow inequality of opportunity and oppression within the social order. Those who have the power and means to communicate these hegemonic 'truths' also have the means and social capital to create and perpetuate them throughout society. In democratic societies, however, the dominant blocs must gain the consent of the masses to legitimate their position of social dominance. This implies that social power is tenuously grasped and is marked by perpetual struggle. One can observe that Foucault's dominant discourse and Gramsci's hegemony may work together to create oppressive mechanisms within the social order: while the former focuses on the production of dominant meanings, the latter examines how blocs use those meanings to manufacture consent.

\section{Neutralizing Social Action}

It appears that counseling's current discourse perpetuates hegemony. Because counselors, for the most part, are considered 'experts' in the diagnosis and treatment of mental health issues (enabled), their intrapsychic discourse, which highlights the internal causes of psychological distress and disorders (constituted), is widely accepted as truth. Consequently, the resultant perception that a client's problems are internally-based, or self-caused, and not the result of chronic, environmentally-caused stress leads individuals to believe that their mental health problems are a result of their own psychological and biological deficiencies. This perception, de facto, constrains any discussion on how systems and forms of oppression may be, or at least may contribute to, the cause of their problems (constrained). Consequently, this extinguishes any impetus for social action and the client invariably focuses his or her energies solely on intrapersonal transformation. Thus, an intrapsychic discourse stabilizes the threat of social change and secures inherent injustices in the prevailing structures of power.

\section{Ecological Counseling Discourse}

Counseling professionals are in a unique position to shape how social reality is perceived. Since theirs is a voice of authority on influences affecting human growth and development, their discourse powerfully constructs descriptions, definitions, and frames of reference by which society understands the relationship between the social order and mental health. Under the current discourse, the mental health of the individual occurs apart from the health of his or her environment. Therefore, despite the heavy influence of toxic environmental factors in the creation and perpetuation of psychological issues, counselors promote the 'reality' that distress and disorders are the result of personal malfunction and inadequacy alone. 
If the profession is to become alert to the need for social justice advocacy and to cease helping perpetuate hegemony in the social order, its perspective needs to shift to include an ecological understanding of human behavior. This shift would naturally construct a new discursive field, one that would conceptualize human behavior as the result of person-environment interaction: $\mathrm{B}=$ $f(P X E)$ (Lewin, 1936). Because of this broader perspective, the meanings produced from the new discourse would inform, organize and address both the intrapersonal aspects of the individual client and the social action needed to remove oppressive barriers in the environment. Since a change in discourse can alter the reality of mental health problems, a counseling discourse that includes an ecological perspective would enable counselors to engage in social justice advocacy.

\section{Application}

The following case study offers considerations and strategies on how counselors can construct a new discursive field that incorporates the person-environment interaction (Lewin, 1936) and moves the profession toward an ecological understanding of human behavior.

Terry, a private practice counselor, has a professional clinical license and has over ten years in the profession. While he has found counseling rewarding, Terry has felt increased frustration about some of his clients' progress. In particular, Terry is working with an African American female client diagnosed with clinical depression. The client, Tamara, meets the DSM-IV TR criteria for chronic Major Depressive Disorder, Moderate. However, Tamara faces significant life stressors, which Terry believes contribute to her diagnosis. For example, Tamara and her husband own their home and she reports that even though they had a high credit score, their mortgage rate is high. As educators, Tamara and her husband have committed to living in the urban community where they teach but have struggled to pay their mortgage due to the high interest rate. Financial strain has led them to secure part-time jobs to supplement their teaching salaries. In addition to these responsibilities, Tamara is the first in her family to graduate from college and her family has significant expectations of her in terms of helping with financial paperwork, providing advice and guidance to nieces and nephews, and church involvement and service. Reporting feelings of being overwhelmed and exhausted, Tamara reported to counseling after a referral from her Employee Assistance Program.

In his clinical approach, Terry has focused on traditional approaches to treating depression symptoms by adopting a cognitive-behavioral approach that emphasizes reorganizing Tamara's cognitive schema to minimize disruptive and negative thoughts. Tamara, however, has a different focus in counseling sessions. She has continually expressed frustration with Terry and his approach; she maintains that he does understand her situation and she rejects the diagnosis of depression. In a tearful exchange during their last session, Tamara told Terry that her community is "under siege." Redlining and 'urban renewal' have led to higher property taxes and foreclosures, thereby forcing many families (who have traditionally lived stably in middle class socioeconomic status) into economic turmoil. Tamara believes that institutional racism contributes to community instability and that while she believes that Terry does care, he just doesn't "get it."

Terry left the session deeply concerned. Not only is he concerned about his ability to empathetically understand Tamara's situation, he reluctantly admitted to himself that although he 
feels connected with his client, he lacks a connection to the larger community in which he counsels. Despite his extensive training in counseling, including advanced degrees and professional conference attendance, Terry notes that his training focuses specifically on 'correcting' the client's intrapsychic self-talk rather than fully exploring the socio-political realities that have shaped his clients' lives. Initially planning to discuss this issue in clinical supervision, Terry decides on a different approach: consult with a community expert on these issues and what they mean for counseling Tamara.

Terry opened the next session explaining his dissonance to Tamara. He indicated that while he could use traditional approaches to counseling to assist her with depression symptoms, Terry wanted to hear more from her about the community and what it means to be a community member. Their ensuing discourse began with Tamara sharing the history of the community and the unfolding of the events that have led to redlining and urban renewal, or the enacting of social and city planning policies that displace existing community members to make room for new wealthier residents (Wolf \& LeBeaux, 1969). Terry became eager to learn more about the community and developed a plan, with Tamara's help, to learn more about the community first hand. First, Terry endeavored to learn about the community. He met with local community organizers who encouraged him to "put away his pen and paper" and engage with community members by shopping in the neighborhood grocery store, attending town hall meetings once per month, and talking with local elders at the community churches and mosque. Terry's own intrapsychic discourse raised objections about 'crossing boundaries' and 'maintaining professional distance.' Nevertheless, he decided to engage in these activities and continue to counsel Tamara once a week.

\section{A Forced Paradigm Shift and New Counselor Client Discourse}

As Terry began his cultural plunge into the community, Terry experienced fear, anger, and even frustration. Unsure of how he would be received by others, Terry did not want to engage with community members as a social experiment. He believed that this was a necessary step in reframing his personal ideology as expressed through his professional counseling. Terry's personal dissonance increased as he realized that many of his assumptions about his clients' motivation and commitment to counseling were framed in an oppressive context. For example, group counseling in the agency begins at 8:30 a.m. However, the local bus schedule is unpredictable due to rush hour and group members have at least a fifteen minute walk to the agency from the closest bus stop. This is not feasible for some but the agency management has been unwilling to change the group meeting time; they maintain that if the clients are motivated, they will come on time. Several clients have been terminated because they were late for group and others faced renewed scrutiny by the courts because of the termination. As he continued to meet with Tamara, Terry shared how his raised awareness had led him to reconsider his previous treatment approaches. He considered that Tamara's socio-political reality likely contributed to her feelings of hopelessness and frustration and that an ecological approach to helping her frame coping and adaptive responses could lead to symptom reduction. Terry's adoption of a less intrapsychic stance became more evident in utilization review staffing. Many of his colleagues found his questions about how agency policy and treatment approaches support clients in engaging in social action and uplift confusing and antithetical to their training and expectations of professional counselors. Some expressed incredulity while others questioned his ability to remain 'objective' and 'neutral.' Terry's emerging social consciousness was not gained without loss of regard by some peers and significant personal cognitive dissonance. However, as he moved 
toward developing a counseling plan with Tamara, he noticed how the counseling alliance improved as he and Tamara incorporated helping strategies indigenous to the community. For example, as Tamara explored her perceptions of the community's expectations of her, she also came to understand that her concerns about the community's continued existence prompted her to accept additional community responsibilities that she could not easily fulfill singlehandedly. Although she espoused a commitment to collective action, Tamara did not trust fully that her efforts would be successful in stopping the external erosion of the community, a "matrix of social life" (Wolf \& LeBeaux, 1967, p. 3) that is a social institution in itself and has provided stability and continuity especially during times of societal upheaval.

\section{Implications for Social Justice Counseling}

This article explored how the current counseling discourse neutralizes counselors' social action. Indeed, the challenges in operationalizing social justice principles into social action can be daunting, particularly in situations where professional training programs and counseling organizations' systemic expectations reinforce and affirm counselors' intrapsychic discourses. Practical steps can be taken, however, to activate social action at various levels of the counseling profession.

First, many of the theories and applications of counseling have historically been applied to support counseling trainees and clients' intrapsychic discourses. While some emerging counseling theories espouse an ecological framework (e.g., feminist counseling and person-ecological counseling), many existing counseling theories can be reconsidered in an ecological framework. For example, Adlerian counseling emphasizes the individual in multiple contexts and promotes ecological reflections of the systemic influences that shape intrapsychic discourse. Similarly, Bronfenbrenner's ecological systems theory offers ways to activate social action at multiple systemic levels.

As the profession retools its current discourse, counseling preparation and professional development programs can be re-oriented to facilitate understanding of clients' multiple realities and the ecological factors that shape them. Teaching counselors the value of moving away from the safety of analyzing clients' intrapsychic spaces begins the ecological discourse. Further, scholarly inquiry can add to the profession's understanding of adopting a holistic and panoramic look at clients' lives. Research could offer empirical support for an ecological perspective which conceptualizes human behavior as a result of person-environment interaction: $B=f(P X E)$ (Lewin, 1936) and define action that confronts environmentally-based oppression that contributes to symptoms of psychopathology.

Finally, embracing clients as experts on their lives and communities facilitates counselors' "putting away the pen and paper" to connect with the larger community can be another step toward activating social action. Connecting with community contextualizes revision of agency policies and procedures that maintain status quo and privilege that comes with financial stability and penalizes those who lack access to reliable transportation, preventive healthcare, and environmentally safe communities. Counselors who connect with their clients and communities in the way that Terry did with Tamara will likely experience significant cognitive dissonance. However, cognitive dissonance is a natural and inevitable result of evolution in one's thinking, being, and ultimately acting. As counseling professionals, though, we understand and 
acknowledge that dissonance shapes the evolution of professional discourse and provides personal and collective power for social action and change.

\section{Conclusion}

The intrapsychic discourse simultaneously constitutes human psychological and emotional problems as internally-based medical conditions, and constrains the recognition of the impact of contextual factors on human development. As a result, counselors are enabled to diagnose and treat their clients' intrapersonal symptoms, but are constrained from addressing the social, political, economic, and cultural factors that impact their clients' development. Moreover, the entrenched discourse extinguishes within clients (as well as most individuals in society) much of the impetus for social action, thus stabilizing the threat of social change and securing inherent injustices in the prevailing structures of power. In order to counter this hegemonic influence, counseling professionals should critically examine their discourse and find ways to replace their intrapsychic-based language and perceptions with a broader, ecological perspective of human behavior. Such a process will undoubtedly cause cognitive dissonance as counselors engage in new meaning making, and actions outside their comfort zone, but these thoughts and feelings are simply signs that counselors have 'put away the pen and paper' - the next step in our profession's evolution.

Contact information:

Arie T. Greenleaf, Ph.D

Assistant Professor, Counselor Education

University of Arkansas

106 Graduate Education Building

Fayetteville, AR 72701

Email: atgreenl@uark.edu

Phone number: (319) 541-8987

Rhonda M. Bryant, PhD, LPC, NCC, NCSC

Associate Professor, School Counseling

Albany State University

504 College Drive

Albany, GA 31705

Email: rmbryant@asurams.edu

Phone number: (229) 430-4686 


\section{References}

Albee, G. W., \& Joffe, J. M. (2004). Mental illness is NOT "an illness like any other". The Journal of Primary Prevention, 24(4), 419-436.

Althusser, L. (2006). Ideology and ideological state apparatuses. In Cultural theory and popular culture: $A$ Reader ( $3^{\text {rd }}$ Ed.). London: Pearson Education.

Baluch, S. P., Pieterse, A. L., Bolden, M. A. (2004). Counseling psychology and social justice Houston...we have a problem. Counseling Psychologist, 32, 89-98.

Breton, M. (1995). The potential for social action in groups. Social work with groups, 18, 5-13.

Clark, R., Anderson, A., Clark, V. R., \& Williams, D. R. (1999). Racism as a stressor for African Americans. American Psychologist, 54, 805-816.

D'Andrea, M. \& Daniels, J. (1999). Exploring the psychology of White racism through naturalistic inquiry. Journal of Counseling \& Development, 77, 93-101.

Dohrenwend, B. P. (2000). The role of adversity and stress in psychopathology: Some evidence and its implications for theory and research. Journal of Health and Social Behavior, 41, 1-19.

Foucault, M. (1972). Archaeology of knowledge. New York: Pantheon.

Freire, P. (1970). Pedagogy of the oppressed. New York: Continuum.

Gramsci, A. (1994). Antonio Gramsci: Pre-prison writings. Cambridge: Cambridge UP.

Gramsci, A. (2006). Hegemony, intellectuals, and the state. In Cultural Theory and Popular Culture: $A$ Reader. ( $3^{\text {rd }}$ Ed.). London: Pearson Education.

Greenleaf, A. T., \& Williams, J. M. (2009). Supporting social justice advocacy: A paradigm shift towards an ecological perspective. Journal for Social Action in Counseling and Psychology, 2(1), 1-14.

Hall. S. (2006). The rediscovery of ideology: The return of the repressed in media studies. In Cultural Theory and Popular Culture: A Reader. ( $3^{\text {rd }}$ Ed.). London: Sage.

Jacobs, D. H. (1994). Environmental failure: Oppression is the only cause of psychopathology. Journal of Mind and Behavior, 15, 1-18.

Kiselica, M. S., \& Robinson, M. (2001). Bringing advocacy counseling to life: The history, issues, and human dramas of social justice work in counseling. Journal of Counseling and Development, 79, 387-397.

Laclau, E. (1993). "Discourse", in A companion to contemporary political philosophy.

(R. E. Goodin and P. Petit, Eds.) London: Blackwell. 
Laclau, E., \& Mouffe. C. (2001). Hegemony and socialist strategy ( ${ }^{\text {nd }}$ Ed.). London: Verso.

Lantz, P. M., House, J. S., Mero, R. P., \& Williams, D. R. (2005). Stress, life events, and socioeconomic disparities in health: Results from the Americans' changing lives study. Journal of Health and Social Behavior, 46, 274-288.

Lee, C. C. (1998). Counselors as agents for social change. In C. C. Lee \& G. R. Walz (Eds.), Social action: A mandate for counselors (pp. 3-16). Alexandria, VA: American Counseling Association.

Lewin, K. (1936). Dynamic theory of personality. New York: McGraw-Hill.

Lewis, J., Arnold, M. S., House, R. \& Toporek, R. (2002). ACA Advocacy Competencies. Retrieved December 3, 2009 from http://www.counseling.org/Publications/

McWhirter, E. H. (1997). Empowerment, social activism, and counseling. Counseling and Human Development, 29, 1-14.

Ortiz-Hernandez, L. (2005). Influence of internalized oppression on the mental health of homosexuals, lesbians, and bisexuals in Mexico City. Salud Mental, 28, 49-65.

Prilleltensky, I. (2008). The role of power in wellness, oppression, and liberation: The promise of psychopolitical validity. Journal of Community Psychology, 36, 116-136.

Ratts, M. J. (2009). Social justice counseling: Toward the development of a "fifth force" among counseling paradigms. Journal of Humanistic Counseling, Education, and Development, $48,160-172$.

Smith, L., Baluch, S., Bernabei, S., Robohm, J., \& Sheehy, J. (2003). Applying a social justice framework to college counseling center practice. Journal of College Counseling, 6, 13.

Storey, J. (2006). Cultural theory and popular culture ( $4^{\text {th }}$ Ed.). Athens, GA: The University of Georgia Press.

Sue, D. W., \& Sue, D. (2003). Counseling the culturally diverse: Theory and practice ( $4^{\text {th }}$ ed.). New York: John Wiley \& Sons.

Szasz, T. (1961). The myth of mental illness: Foundations of a theory of personal conduct. Harper \& Row.

Toporek, R.L., Gerstein, L., Fouad, N., Roysircar, G. S., Israel, T. (Eds.) (in press). Handbook for social justice in counseling psychology: Leadership, vision, \& action. Thousand Oaks, CA: Sage.

Trickett, E. J. (1997). Ecology \& primary prevention: Reflections on a meta-analysis. American Journal of Community Psychology, 25, 197-205. 
Vera, E. M., \& Speight, S. L. (2003). Multicultural competence, social justice, and counseling psychology: Expanding our roles. Counseling Psychologist, 31, 253-272.

Williams, D. R., \& Williams-Morris, R. (2000). Racism and mental health: The African American experience. Ethnicity and Health, 5, 243-268.

Wolf, E.P., \& LeBeaux, C. (1967). Class and race in the changing city: Searching for new approaches to old problems. In L. F. Schnore (ed.), Social Science and the City. New York: Praeger.

Worell, J., \& Remer, P. (2003). Feminist perspectives in therapy: Empowering diverse women. ( $2^{\text {nd }}$ Ed.). Hoboken, NJ: John Wiley \& Sons. 